\title{
Modelagem do volume e do peso da casca de Bracatinga (Mimosa scabrella - Bentham) na região metropolitana de Curitiba, Paraná (doi:10.4136/ambi-agua.11)
}

\section{Sebastião do Amaral Machado'; Luís César Rodrigues da Silva²; Edilson Urbano³; Marco Aurélio Figura ${ }^{4}$; Saulo Jorge Téo ${ }^{5}$ : Lorena Stolle ${ }^{6}$}

\author{
${ }^{1}$ Prof. Sênior do Dep. de Ciências Florestais da UFPR, Eng. Florestal M. Sc., Ph.D. - Pesq. 1A do CNPq \\ E-mail: sammac@floresta.ufpr.br \\ ${ }^{2}$ Graduando em Enga . Florestal, UFPR, Bolsista CNPq - ${ }^{2}$ Graduando em Eng ${ }^{\mathrm{a}}$. Florestal, UFPR \\ E-mail: nabravomova@hotmail.com \\ ${ }^{3}$ Eng. Florestal, mestrando em Eng ${ }^{\mathrm{a}}$. Florestal, UFPR \\ E-mail: edurbano2@hotmail.com \\ ${ }^{4}$ Graduando em Enga . Florestal, UFPR, bolsista CNPq \\ E-mail: figura_floresta@hotmail.com \\ ${ }^{5}$ Graduando em Eng ${ }^{\mathrm{a}}$. Florestal, UFPR, bolsista CNPq \\ E-mail: sauloteo@yahoo.com.br \\ ${ }^{6}$ Eng. Florestal Mestrando em Enga . Florestal, UFPR, bolsista CNPq \\ E-mail: lorenastolle@yahoo.com.br.
}

\section{RESUMO}

Este trabalho teve como objetivo a modelagem do volume e do peso da casca da bracatinga (Mimosa scabrella Bentham). Foram cubadas 440 árvores de bracatinga pelo método relativo de Hohenadl para 10 seções, com idades de 6 a 17 anos, em vários municípios da região metropolitana de Curitiba, Paraná. Os fustes de 194 árvores foram pesados no campo. Amostras de casca dessas árvores foram coletadas, pesadas no campo (peso verde) e trazidas para secagem até peso constante (peso seco), possibilitando assim calcular a relação peso seco/peso verde da amostra e extrapolação para todo o fuste. Por meio da literatura foram selecionados modelos tradicionalmente usados em estimativas de volume. Foram também gerados modelos próprios com as variáveis que mais se correlacionavam com o peso e o volume da casca da bracatinga. Ao todo foram ajustados 20 modelos, sendo utilizado o peso $1 / \mathrm{d}^{2} \mathrm{~h}$ para a ponderação dos modelos aritméticos de dupla entrada e $1 / \mathrm{d}^{2}$ para os de simples entrada. Os melhores modelos foram então selecionados, com base no seu desempenho em relação ao coeficiente de determinação ajustado $\left(R_{a j}^{2}\right)$, erro padrão da estimativa em porcentagem $\left(s_{y x}\right)$ e distribuição gráfica dos resíduos. No geral, os modelos próprios, compostos com as variáveis de maior correlação, foram os mais precisos. Os melhores ajustes foram obtidos para o volume e o peso verde da casca, com $s_{y x} \%$ variando de 15 a $18 \%$ e $R_{a j}^{2}$ de 0,96 a 0,98 . Já quando se estimou o volume da casca em porcentagem, o melhor modelo para esta situação apresentou um $R_{a j}^{2}$ de apenas 0,47 e $s_{y x}$ de $17 \%$. Quando se estimou o peso seco da casca, os melhores modelos apresentaram $s_{y x \%}$ maiores e $R^{2}{ }_{a j}$ mais baixos do que os obtidos para peso verde.

Palavras-chave: Mimosa scabrella; biomassa; estimativa; inventário florestal; modelagem.

\section{Bark volume and weight modeling of Mimosa scabrella Bentham trees in the Curitiba metropolitan region}

\section{ABSTRACT}

The objective of this paper was to model bark volume and weight of Mimosa scabrella Bentham trees. To achieve this objective 440 trees were cubed by the Hohenadl's method using 10 sections. These trees had ages ranging from 6 to 17 years, and were located in 
several counties inside the Curitiba (Parana) metropolitan region. The stems from 194 trees were weighed in the field. Samples of bark from these trees were collected, weighed in the field (green weight) and brought to the laboratory for drying until constant weight (dry weight); thus it was calculated the relationship dry weight/green weight of the sample and extrapolation for the whole stem. For the modeling, several mathematical models from the literature for estimating dry weight of Acacia mearnsii were selected. New models based on the forward's method were also built. Twenty different models were adjusted using the $1 / \mathrm{d}^{2} \mathrm{~h}$ to weight the arithmetic models with two entries and $1 / \mathrm{d}^{2}$ for the models with single entry. The best models for each case were selected basing on the adjusted coefficient of determination $\left(R_{a j}^{2}\right)$, standard error of estimate in percentage $\left(s_{y x} \%\right)$ and on the residual graphic distribution. In general, the new models built with variables most correlated with the respective independent variables were the most precise. The best fitting were obtained for bark volume and green weight, with $s_{y x}$ ranging from 15 to $18 \%$, and $R^{2} a j$ from 0.96 to 0.98 . The best equation for estimating bark volume in percentage presented $R_{a j}^{2}=0.47$ and $s_{y x \%}=$ $17 \%$.The best models for estimating bark dry weight presented higher $s_{y x}$ and lower $R_{a j}^{2}$ than those obtained for green weight.

Keywords: Mimosa scabrella; biomass; estimative; forest inventory; modeling.

\section{INTRODUÇÃO}

A Mimosa scabrella, da família Mimosaceae, é uma espécie exclusiva da vegetação secundária da floresta ombrófila mista de formação Montana e Altomontana, de clima frio e úmido. É encontrada, principalmente, na forma de bosques conhecidos como bracatingais. Bracatinga como é conhecida, é a pioneira mais importante na região da Araucaria angustifolia. Forma agrupamentos densos e é manejada em povoamentos homogêneos com finalidade energética e madeireira (Bakes; Irgang, 2002).

Heliófita de rápido crescimento e pouco exigente quanto às condições de solo. A idade ideal de corte vai depender da necessidade do mercado, da finalidade de aproveitamento da madeira e dos objetivos da empresa. De uma maneira geral, pode-se preconizar a idade de 4 a 7 anos como a de máxima produção biológica (Reitz et al., 1988).

Embrapa (1988) registrou três variedades: a bracatinga branca, que é a mais abundante e preferida por ser mais fácil de trabalhar; a vermelha, que tem madeira mais dura e avermelhada e ocorre em menor quantidade junto com a variedade branca e por fim, a variedade argentina, que tem crescimento mais rápido, tem folhas mais claras e os frutos e sementes são maiores e mais rugosos.

A espécie ocupa grandes superfícies da área metropolitana de Curitiba e outras, principalmente nos estados do Paraná e Santa Catarina, na forma de densas associações em que cerca de $61 \%$ correspondem à bracatinga e o restante engloba mais de 80 espécies (Baggio, 1994).

Silva e Paula Neto (1979) constataram que a casca pode representar até $25 \%$ do volume do fuste, dependendo da espécie e do local onde ela se encontra. Para Husch et al. (1982), esse valor chega no máximo a 20\%. Esse autor destacou o método do fator de casca "K" para se determinar o volume de casca em porcentagem e afirmou que dá resultados mais acurados para a maioria dos propósitos.

O método do fator de casca foi desenvolvido por Meyer (1946), que deduziu a fórmula para calcular o volume de casca em porcentagem, usando apenas os diâmetros com e sem casca à altura do peito. $\mathrm{O}$ autor concluiu que $\mathrm{K}$ é constante ao longo do fuste e também desenvolveu uma metodologia para estimar a espessura de casca. Machado e Garcia (1984) testaram tal metodologia em plantações de Pinus taeda e concluíram que o fator de casca K 
não foi constante ao longo do fuste e que a fórmula de Meyer superestimou muito o volume de casca em porcentagem para todas as classes de diâmetro. Mais tarde, Machado e Silva (2006) aplicaram a mesma metodologia em bracatingais da região metropolitana de Curitiba, Paraná, e observaram a mesma inconstância no valor de K. Nunes (1981) estudou a porcentagem de casca em três espécies do gênero Eucalyptus e da mesma forma constatou uma inconstância no fator K ao longo do fuste. Loetsch et al. (1973) já haviam afirmado que a relação entre espessura de casca e DAP depende de influências específicas como clima, idade e sítio e que a relação entre diâmetro sem casca e diâmetro com casca pode ser ou não constante ao longo do tronco, dependendo da espécie. Até certa altura a casca é grossa, mudando, então, abruptamente em algum ponto em direção à extremidade mais fina.

Schneider (1978) elaborou tabelas para avaliar o peso verde e seco de casca de Acácia negra (Acacia mearnsii) e em todos os modelos de equações sugeridos por ele pelo procedimento Forward, estava presente a variável $d^{2} h$, mostrando que a combinação do diâmetro a 1,30m de altura (d) com a altura (h) forneceu alta correlação com a variável dependente peso de casca.

Batista et al. (2004) destacaram que, de uma ampla lista de modelos volumétricos propostos na literatura, apenas dois modelos têm uso generalizado que são o modelo da variável combinada de Spurr e o logaritmo de Schumacher e Hall.

Desde 1909, quando começou o estímulo do plantio da bracatinga para atender demandas energéticas, essa espécie desempenha um papel importante na economia da região metropolitana de Curitiba, Paraná, onde ocupa aproximadamente 60.000 ha (Grodzki et al., (2004) citaram área de 85.000 ha), distribuídos, principalmente, em pequenas propriedades. É tradicionalmente manejada de uma forma conhecida como "Sistema Agroflorestal da Bracatinga”. Nele se associam culturas agrícolas no ano de implantação e após o corte final, costuma-se queimar a área para induzir a regeneração de outro bracatingal (Embrapa, 1988; Laurent et al., 1990). Trata-se de uma fonte de renda segura e com baixa requisição de mãode-obra para o produtor. O principal destino é mesmo a produção de energia como carvão e lenha para indústrias e residências, embora já existam usos mais nobres como produção de celulose, compensados e até móveis.

Hoje a forma tradicional de condução da bracatinga já é alvo de críticas como a de Baggio e Carpanezzi (1997), que mostraram que a exportação de nutrientes pela lenha tem reposição economicamente inviável e sugeriram mudanças nas práticas do sistema de manejo para equilibrar o balanço de nutrientes. Da mesma forma, comentou Bartoszeck (2000), destacando que o manejo tradicional pode não ser a maneira mais adequada de condução da bracatinga. Por outro lado, estudos tentam otimizar a espécie, agregando valor cultural e econômico, como relatado em Fabrowski (1998), que identificou compostos na casca da bracatinga que podem ser explorados como taninos e alcalóides, ou aquele de Baggio e Carpanezzi (1995), que estudaram a utilização dos resíduos da exploração de bracatingais, ao invés de simplesmente queimá-los.

Estimativas em florestas é um problema relevante na Silvimetria. Tal estimativa é de fundamental importância, pois é suporte para a tomada de decisões no manejo e planejamento florestais. Assim o presente trabalho teve como objetivo testar modelos matemáticos para estimativas do volume da casca, volume da casca em porcentagem, peso verde da casca e peso seco da casca de bracatinga, para aquelas situações em que for necessária uma quantificação da casca para posterior utilização. 


\section{MATERIAL E MÉTODOS}

\subsection{Coleta dos Dados}

O trabalho foi realizado em bracatingais formados por regeneração natural induzida, pertencentes a diversos proprietários, com idades variando de 6 a 17 anos, localizados em alguns municípios que compõem a região metropolitana de Curitiba, Paraná, ao norte da capital, sendo eles: Tunas do Paraná, Rio Branco do Sul, Almirante Tamandaré, Bocaiúva do Sul, Colombo e Campina Grande do Sul.

A região encontra-se no primeiro planalto do Paraná com altitudes variando de 850 a 950 m, clima tipo Cfb segundo classificação de Köppen, em que se registram temperaturas médias anuais em torno de 16 a $17{ }^{\circ} \mathrm{C}$ e a precipitação anual atinge $1500 \mathrm{~mm}$.

Para a construção das equações de volume da casca foram cubadas 440 árvores pelo método relativo de Hohenadl, distribuídas numa amplitude diamétrica de 4 a $30 \mathrm{~cm}$. Os fustes de 194 árvores foram pesados no campo. Amostras de casca dessas árvores foram coletadas, pesadas no campo (peso verde) e trazidas para secagem até peso constante (peso seco), possibilitando assim calcular a relação peso verde/peso seco da amostra e extrapolação para todo o fuste. Dessa forma, obtiveram-se os pesos de casca verde e seco de cada fuste das 194 árvores.

\subsection{Modelagem}

Para as variáveis dependentes volume de casca verde $(v c)$, volume de casca verde em porcentagem $(v c \%)$, peso verde da casca $(p v)$ e peso seco da casca $(p s)$, foram ajustados 20 modelos, aritméticos e logarítmos, citados na literatura (Tabela 1). Também foram gerados mais 5 modelos aritméticos com base numa matriz de correlação simples da seguinte forma: com as variáveis independentes coletadas no campo, espessura de casca (e), diâmetro a 1,30m de altura $(d)$, idade $(i d)$, altura do fuste $(h)$, foram feitas dezenas de combinações e as que apresentaram correlações simples mais altas (acima de 0,9) com as variáveis dependentes foram selecionadas para serem usadas como variáveis independentes na montagem de modelos usando o processo Forward, disponível no software Statgraphics 4.1. Esse programa produziu todas as combinações possíveis para as variáveis independentes fornecidas, bem como o coeficiente de determinação ajustado $\left(R_{a j}^{2}\right)$ para cada possível combinação. Foram selecionadas as melhores combinações para volume e peso, considerando um $R_{a j}^{2}$ alto e o menor número possível de variáveis independentes (Tabela 1).

Os modelos de melhor ajuste foram escolhidos com base no seu desempenho quanto ao coeficiente de determinação ajustado $\left(R_{a j}^{2}\right)$, erro padrão da estimativa em porcentagem $\left(s_{y x}\right)$ e distribuição dos resíduos. Para os modelos aritméticos, foi feito um ajuste ponderado para corrigir a heterogeneidade da variância do erro. O peso $\frac{1}{d^{2}}$ foi usado para os modelos de simples entrada, já para os modelos de dupla entrada, a ponderação usada foi $\frac{1}{d^{2} h}$. Em relação aos modelos logaritmizados, não ocorre heterogeneidade de variância dos erros porque a transformação logarítmica tende a corrigi-la (Batista et al., 2004). Apenas a discrepância logarítmica foi tratada, usando-se o fator de correção de Meyer. 
Tabela 1. Modelos matemáticos testados para a estimativa do volume de casca verde $(v c)$, volume de casca verde em porcentagem $(v c \%)$, peso seco $(p s)$ e peso verde $(p v)$.

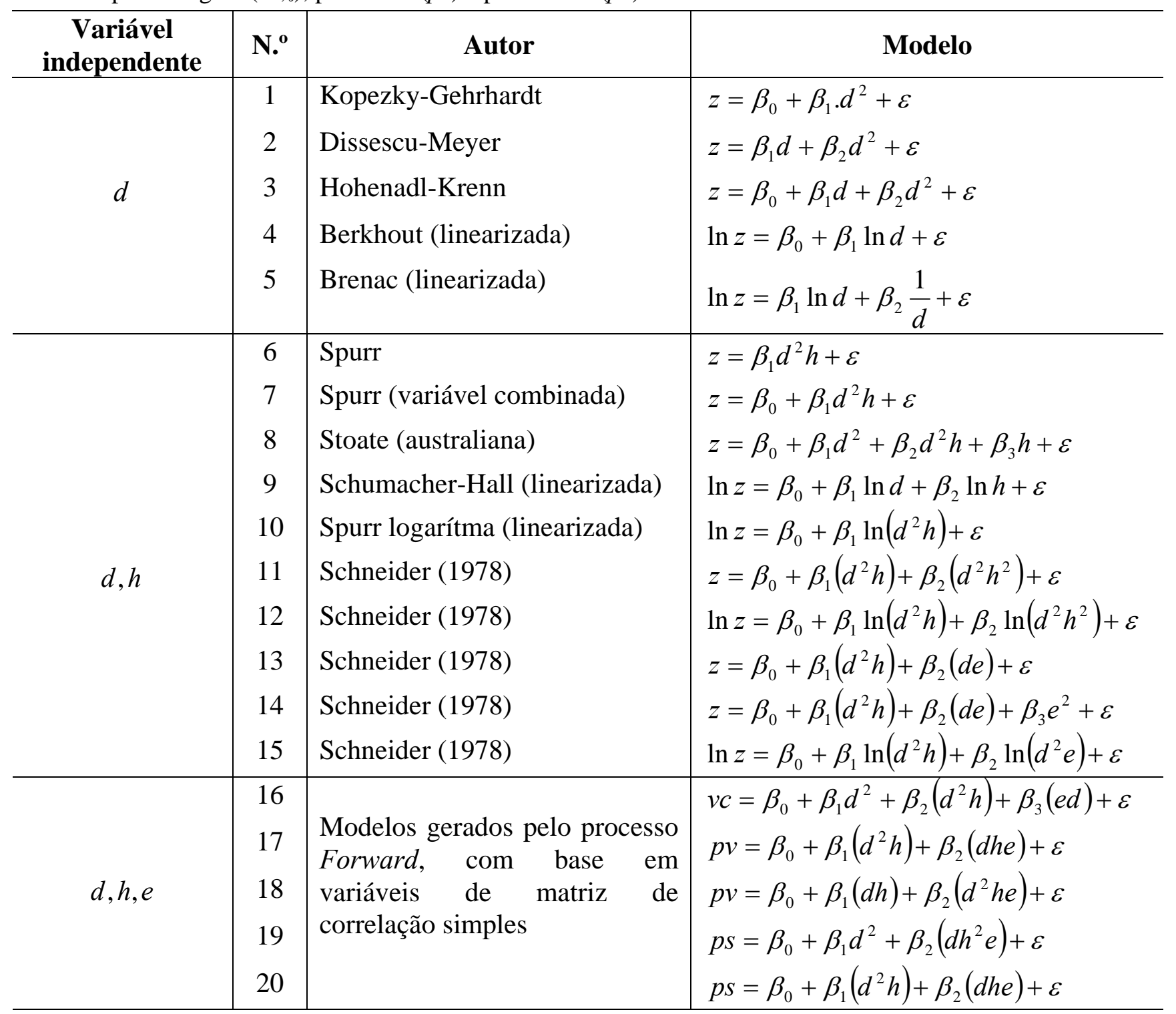

Onde: $z=(v c)$ ou $(v c \%)$ ou $(p s)$ ou $(p v)$.

$v c=$ volume de casca individual verde $\left(\mathrm{m}^{3}\right)$

$v c_{\%}=$ volume de casca individual verde $(\%)$

$p s=$ peso seco da casca $(\mathrm{kg})$

$d=$ diâmetro com casca a $1,30 \mathrm{~m}$ do solo $(\mathrm{cm})$

$p v=$ peso verde da casca $(\mathrm{kg})$

$e=$ espessura simples de casca $(\mathrm{cm})$

$h=$ altura do fuste $(\mathrm{m})$

$\varepsilon=$ erro estatístico

$\beta=$ coeficiente ajustado

\section{RESULTADOS E DISCUSSÃO}

\subsection{Características dos Dados}

O tamanho inicial da amostra foi reduzido tanto para o volume da casca quanto para o peso da casca, em conseqüência da presença de dados discrepantes, apontados pelos gráficos de resíduos, elaborados no decorrer dos ajustes. A Tabela 2 apresenta as estatísticas das variáveis utilizadas nos ajustes. 
Tabela 2. Estatística descritiva das variáveis usadas na construção dos modelos.

\begin{tabular}{l|c|c|c|c|c}
\hline \multirow{2}{*}{ Variável } & \multicolumn{5}{c}{ Estatística } \\
\cline { 2 - 6 } & $\begin{array}{c}\text { Tamanho } \\
\text { da amostra }\end{array}$ & $\begin{array}{c}\text { Valor } \\
\text { Mínimo }\end{array}$ & Média & $\begin{array}{c}\text { Valor } \\
\text { Máximo }\end{array}$ & cV\% \\
\hline DAP (cm) & 411 & 4,6 & 12,8 & 30,6 & 47,7 \\
Espessura casca (cm) & 411 & 0,2 & 0,44 & 1,0 & 42,2 \\
Altura fuste (m) & 411 & 3,3 & 8,9 & 15,4 & 27,9 \\
Volume casca (\%) & 411 & 9,0 & 14,51 & 24,2 & 18,4 \\
Volume casca verde (m $\left.{ }^{3}\right)$ & 411 & 0,0010 & 0,0148 & 0,0768 & 96,4 \\
Peso casca verde (kg) & 181 & 1,3 & 17,6 & 74,3 & 98,9 \\
Peso casca seca $(\mathrm{kg})$ & 181 & 0,6 & 7,2 & 26,1 & 91,0 \\
\hline
\end{tabular}

Como se observa na Tabela 2, a variabilidade do DAP, da espessura da casca, da altura do fuste, do volume da casca em porcentagem é relativamente baixa. No entanto, o volume da casca verde e os pesos verde e seco da casca têm uma amplitude de variação alta. A espessura da casca da bracatinga é relativamente baixa, principalmente se comparada às espécies coníferas, conforme detectado por Machado e Garcia (1984), no entanto, o volume da casca em termos percentuais é relativamente maior do que o da maioria das folhosas, e seu valor máximo ultrapassando 24\% mostra que Silva e Paula Neto (1979) estavam certos, quando constataram que a porcentagem de casca de um fuste pode atingir $25 \%$ do volume total e não apenas 20\% como afirmado por Husch et al. (1982).

Para observar o comportamento da casca no fuste da bracatinga, foram elaboradas as Figuras 1 e 2, que mostram, respectivamente, a porcentagem da casca no fuste, ao longo das classes de DAP e o quanto dessa porcentagem de casca representa apenas o peso de matéria seca utilizável. Comparando os dois gráficos, observa-se que os menores diâmetros têm uma tendência a ter uma porcentagem de casca um pouco maior (Figura 1) e nessa mesma porcentagem de casca, o peso seco também é maior que nas classes de DAP maiores (Figura 2), ou seja, há mais matéria seca, em porcentagem, na casca dos menores diâmetros.

Na Tabela 3 são apresentados os melhores resultados de uma matriz de correlação simples, envolvendo as variáveis dependentes volume e peso da casca e dezenas de outras variáveis independentes, sendo que apenas as correlações acima de 0,9 foram utilizadas. Nessa tabela pode ser observado que o volume da casca expresso em porcentagem ( $v c \%)$, não se correlacionou satisfatoriamente com nenhuma variável independente, por isso essa variável não foi utilizada para a elaboração de modelos matemáticos. Ainda pode ser verificado que embora as variáveis espessura da casca $(e)$ e altura do fuste $(h)$ não apresentassem correlação satisfatória quando usadas individualmente, quando combinadas com outras variáveis independentes, seus desempenhos melhoraram consideravelmente. Embora a variável idade

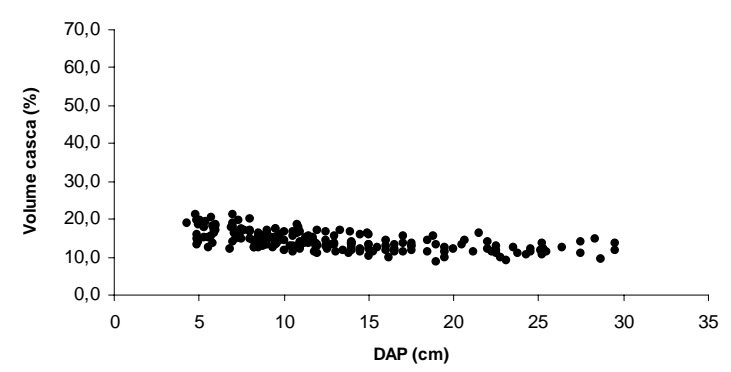

Figura 1. Volume da casca em porcentagem, ao longo das classes diamétricas. 


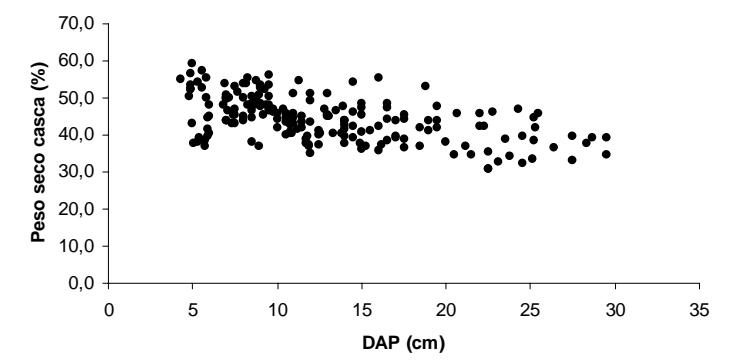

Figura 2. Peso seco da casca em porcentagem, ao longo das classes diamétricas.

tenha sido utilizada para compor a matriz de correlação, essa não apresentou boas correlações e por isso não aparece na Tabela 3 que apresenta somente as variáveis independentes cuja correlação foi acima de 0,9 com alguma variável dependente.

A partir dessa matriz foram ajustados os modelos 16, 17, 18, 19 e 20 da Tabela 1, como já explicado anteriormente.

Tabela 3. Matriz de correlação simples entre variáveis dependentes e independentes.

\begin{tabular}{|c|c|c|c|c|c|c|c|c|c|c|c|c|}
\hline & $d$ & $e$ & $H$ & $d^{2} h$ & $d^{2}$ & $d h$ & ed & eh & $d^{3}$ & dhe & $d^{2} h e$ & $d h^{2} e$ \\
\hline VC & 0,93 & 0,88 & 0,48 & 0,96 & 0,94 & 0,91 & 0,94 & 0,91 & 0,91 & 0,97 & 0,96 & 0,95 \\
\hline $\mathrm{VC}_{\%}$ & $-0,53$ & $-0,19$ & $-0,45$ & $-0,47$ & $-0,45$ & $-0,54$ & $-0,31$ & $-0,33$ & $-0,37$ & $-0,35$ & $-0,31$ & $-0,35$ \\
\hline$p v$ & 0,92 & 0,83 & 0,54 & 0,97 & 0,93 & 0,94 & 0,91 & 0,90 & 0,91 & 0,97 & 0,96 & 0,95 \\
\hline$p s$ & 0,92 & 0,84 & 0,55 & 0,95 & 0,92 & 0,93 & 0,91 & 0,90 & 0,90 & 0,96 & 0,94 & 0,93 \\
\hline & $\begin{array}{l}v c= \\
v c c_{\%}= \\
p v= \\
p s= \\
d=\mathrm{D} \\
e=\mathrm{es} \\
h=\mathrm{a}\end{array}$ & $\begin{array}{l}\text { olume i } \\
\text { volume } \\
\text { eso ve } \\
\text { eso sec } \\
\text { AP com } \\
\text { gessura } \\
\text { ura do f }\end{array}$ & $\begin{array}{l}\text { dividua } \\
\text { ndividu } \\
\text { de da c } \\
\text { da cas } \\
\text { asca (c } \\
\text { e casca } \\
\text { ste (m) }\end{array}$ & $\begin{array}{l}\text { de casc } \\
\text { de cas } \\
\text { sca (kg } \\
\text { a (kg) } \\
\text { ) } \\
\text { cm) }\end{array}$ & $\begin{array}{l}\left(\mathrm{m}^{3}\right) \\
(\%)\end{array}$ & & & & & & & \\
\hline
\end{tabular}

\subsection{Modelagem}

\subsubsection{Volume da Casca}

De todos os modelos ajustados para prever o volume da casca $(v c)$, os modelos 15 e 16 foram os melhores segundo os critérios de seleção utilizados. Na Tabela 4, são apresentados os coeficientes, os $R_{a j}^{2}$, os $s_{y x}$ e o gráfico da distribuição dos resíduos desses modelos, bem como o fator de Meyer para o modelo logarítmico de número 15. O que mais influenciou na escolha de tais modelos foi a estatística de precisão $\left(s_{y x}\right)$ que foi mais baixa que a dos demais modelos. Mesmo assim, o valor de $s_{y x}$ foi acima de 15 , valor aquém do esperado para um modelo considerado de ótima precisão, mas o fato positivo de tais modelos é que não apresentaram tendenciosidade ao longo das classes diamétricas, como mostram os gráficos de resíduos inseridos na Tabela 4. Isso indica que tais modelos podem ser usados para estimar o volume de casca de árvores de bracatinga tendo em vista que os erros para mais e para menos se compensam.

Quando os modelos foram ajustados para estimar o volume da casca em porcentagem $(v c \%)$, o de melhor desempenho, como mostra a Tabela 5, obteve um coeficiente de determinação ajustado $\left(R_{a j}^{2}\right)$ de apenas 0,47 , porém a precisão $\left(s_{y x} \%\right)$ foi semelhante à situação anterior, assim como o gráfico de resíduos não apresentou tendenciosidade ao longo das classes diamétricas. Então, pode-se considerar esse modelo também útil quando não é exigida 
uma precisão alta para estimar o volume de casca em porcentagem do fuste da bracatinga. Como se trabalhou com valores percentuais, foram também testados para essa situação, sem sucesso, ajustes com os dados transformados.

O modelo mostrado na Tabela 5, para prever o volume de casca em porcentagem, é, por enquanto, uma boa opção já que uma outra alternativa, a metodologia desenvolvida por Meyer (1946), para essa finalidade, já foi testada, sem sucesso, por Machado e Silva (2006) em bracatingais.

Outro fato é que não houve qualquer variável independente que se correlacionasse satisfatoriamente com o volume de casca em porcentagem, como pôde ser observado na Tabela 3. Isso pode explicar o $R_{a j}^{2}$ baixo apresentado pelo melhor modelo. Por essa baixa correlação com variáveis independentes é que o volume de casca em porcentagem não foi incluído no processo Forward de composição de modelos.

Tabela 4. Melhores modelos para avaliar volume de casca verde $(v c)$ com seus respectivos coeficientes e estatísticas de ajuste e precisão.

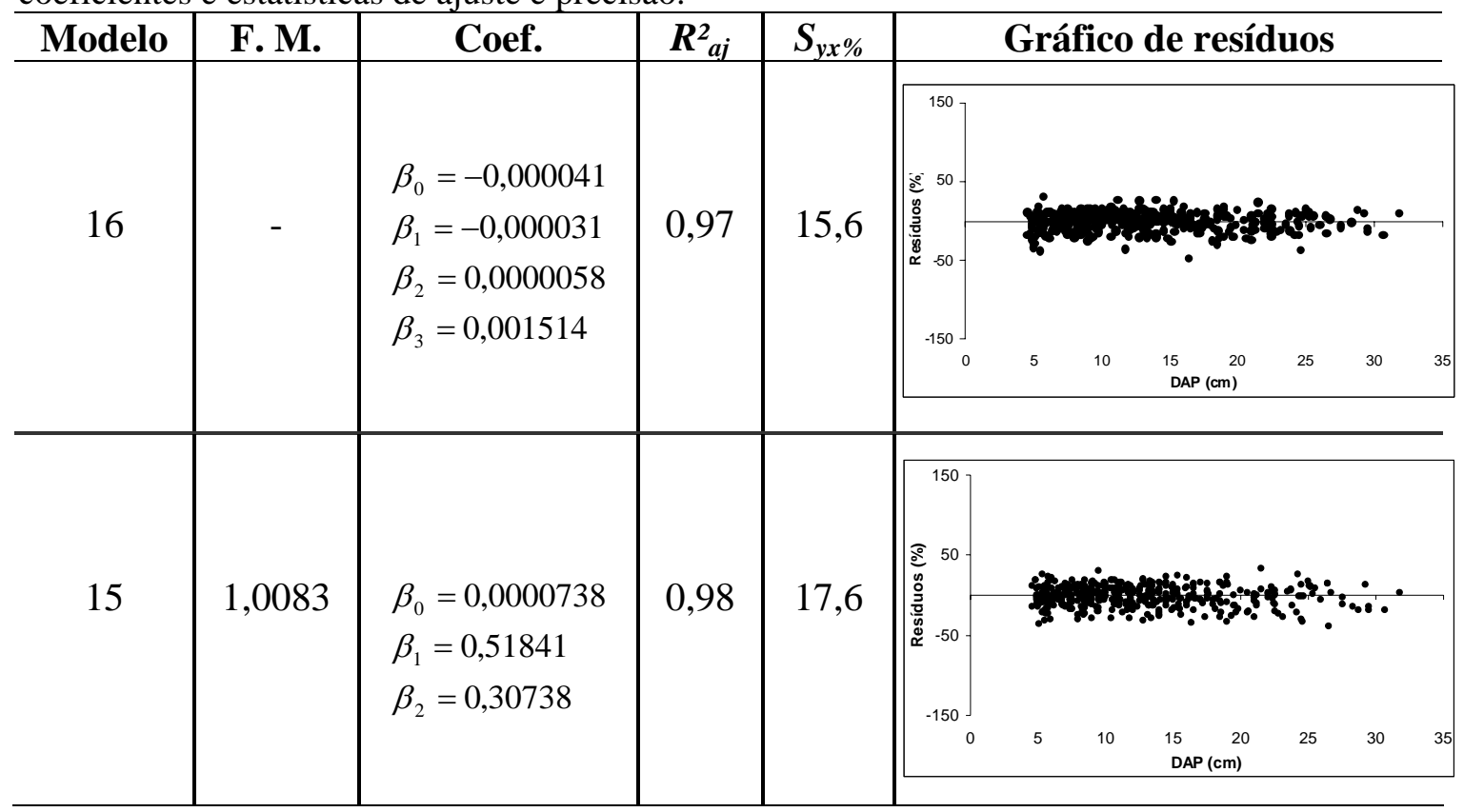

Onde: F. M. = Fator de correção de Meyer para modelos logaritmos Coef $=$ Coeficientes ajustados $R_{a j}^{2}=$ Coeficiente de determinação ajustado $S_{y x \%}=$ Erro padrão da estimativa em porcentagem

No geral, percebe-se que o modelo 15, construído por Schneider (1978), também foi adequado tanto para estimar o volume em metros cúbicos quanto para estimar o volume da casca em percentagem de bracatinga. Modelos tradicionais como os de Schumacher \& Hall e Spurr, embora tenham apresentado $R_{a j}^{2}$ superior a 0,96 , tiveram erro $\left(s_{y x}\right)$ maior que $25 \%$. 
Tabela 5. Melhor modelo para avaliar volume de casca verde em porcentagem $(v c \%)$ com seu respectivo coeficiente e estatística de ajuste e precisão.

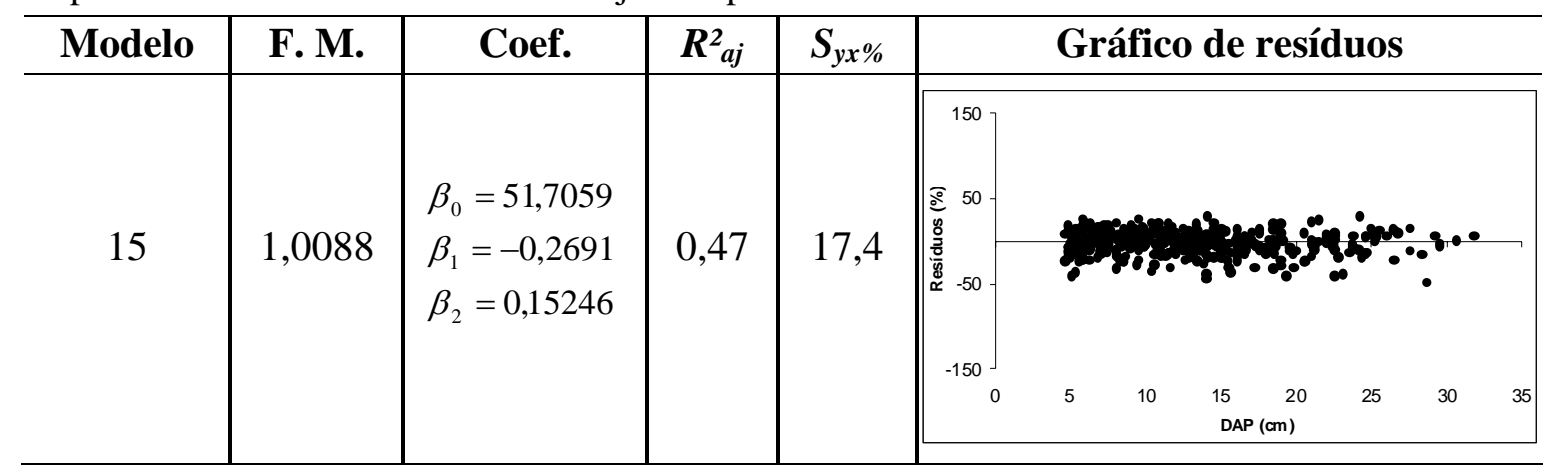

\subsubsection{Peso da Casca}

Considerando o peso verde da casca, os modelos de melhor ajuste foram os 14, 17 e 18 (Tabela 6), por apresentarem desempenhos similares. Dos três modelos, destaca-se o 14 que apesar de ter um erro $\left(s_{y x} \%\right)$ um pouco maior que o modelo 17, apresentou uma distribuição de resíduos menos dispersa. Isso indica que das três alternativas, o modelo 14 seria o mais recomendado para estimar o peso verde da casca de bracatinga. Esse modelo está entre os sugeridos por Schneider (1978) para prever o peso verde e seco da casca de acácia negra (Acacia mearnsii). Como pode ser visualizado na Tabela 6, o ajuste desse modelo resultou num $R^{2}{ }_{a j}$ de 0,97 contra 0,93 encontrado por Schneider. Já o $s_{y x}$ foi de 18,1\% ou $s_{y x}$ $= \pm 3,1853 \mathrm{~kg}$, enquanto que Schneider encontrou um $s_{y x}$ de $\pm 2,2005 \mathrm{~kg}$ para o mesmo modelo.

Quando se ajustaram os modelos para estimar o peso seco da casca ( $p s)$, o resultado foi diferente do produzido por Schneider. Os modelos gerados por ele, usando o processo Forward de seleção, estimavam, ao mesmo tempo, o peso verde e o peso seco da casca, ou seja, os modelos tinham o mesmo arranjo de variáveis independentes para prever as duas situações.

Na presente pesquisa, o processo Forward gerou quatro modelos para estimativas do peso da casca (Tabela 1, modelos de 17 a 20), sendo dois para estimar o peso verde e dois para o peso seco da casca, porém, apenas um tem o mesmo arranjo de variáveis independentes para as duas situações. Trata-se do modelo 17, gerado pelo processo para estimar a variável dependente peso verde da casca e que depois foi gerado novamente quando se considerou o peso seco da casca como variável dependente (modelo 20).

Levando em consideração os resultados obtidos por Schneider, esperava-se que o processo Forward gerasse apenas modelos idênticos para estimar o peso verde e o peso seco da casca da bracatinga também. Ocorreu que tal processo acabou gerando o modelo 18 que é exclusivo para estimar o peso verde da casca e o modelo 19 que é exclusivo para estimativas sobre o peso seco da casca. Entende-se então que, nem sempre, o processo gera um arranjo idêntico de variáveis para prever situações parecidas como o caso dos pesos verde e seco da casca em que a diferença entre ambos é a presença de água no peso verde.

Como pode ser constatado nas Tabelas 6 e 7, os modelos gerados pelo processo Forward estão presentes entre os selecionados como os melhores, de acordo com os critérios adotados para a seleção deles, mostrando que é um recurso útil quando se procura construir modelos matemáticos.

Considerando os resultados obtidos para as estimativas do peso seco da casca da bracatinga, não se recomenda o uso dos modelos indicados na Tabela 7 para estimar o peso seco da casca de árvores com diâmetros pequenos porque, como pode ser visto no gráfico de 
resíduos dos modelos constantes em tal tabela, há tendência de superestimativa do peso seco da casca para árvores com tais diâmetros.

No geral, a variável $d^{2} h$ foi a que mais contribuiu para a eficiência dos melhores modelos, pois teve a maior correlação com as variáveis dependentes. Nos modelos desenvolvidos por Schneider para a acácia negra, essa variável esteve sempre presente, mostrando que é uma variável que não pode deixar de ser testada, quando se desejam modelos eficientes para estimativas com relação à casca.

Tabela 6. Melhores modelos para avaliar peso verde da casca ( $p v)$ com seus respectivos coeficientes e estatísticas de ajuste e precisão.

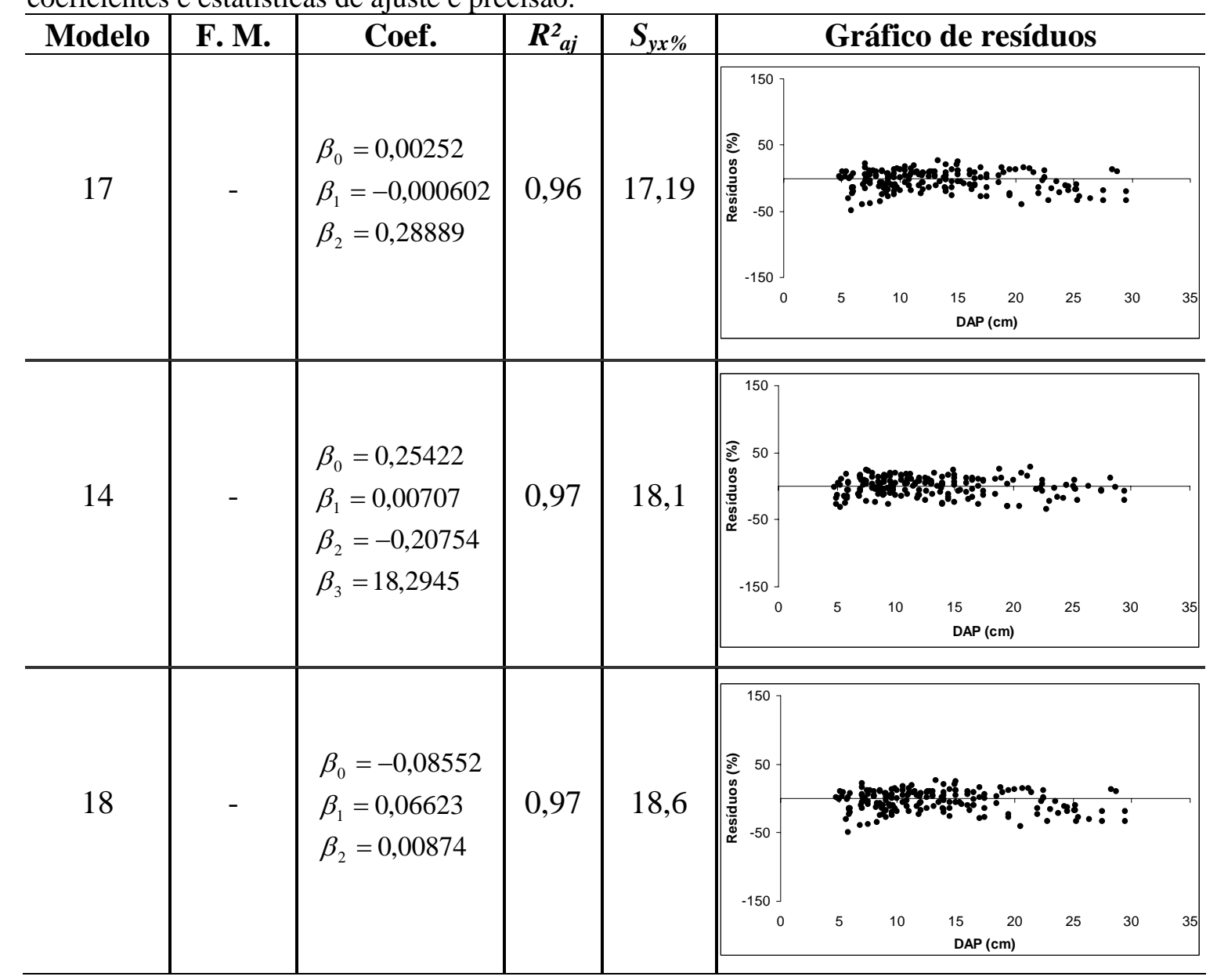


Tabela 7. Melhores modelos para avaliar peso seco da casca ( $p s$ ) com seus respectivos coeficientes e estatísticas de ajuste e precisão.

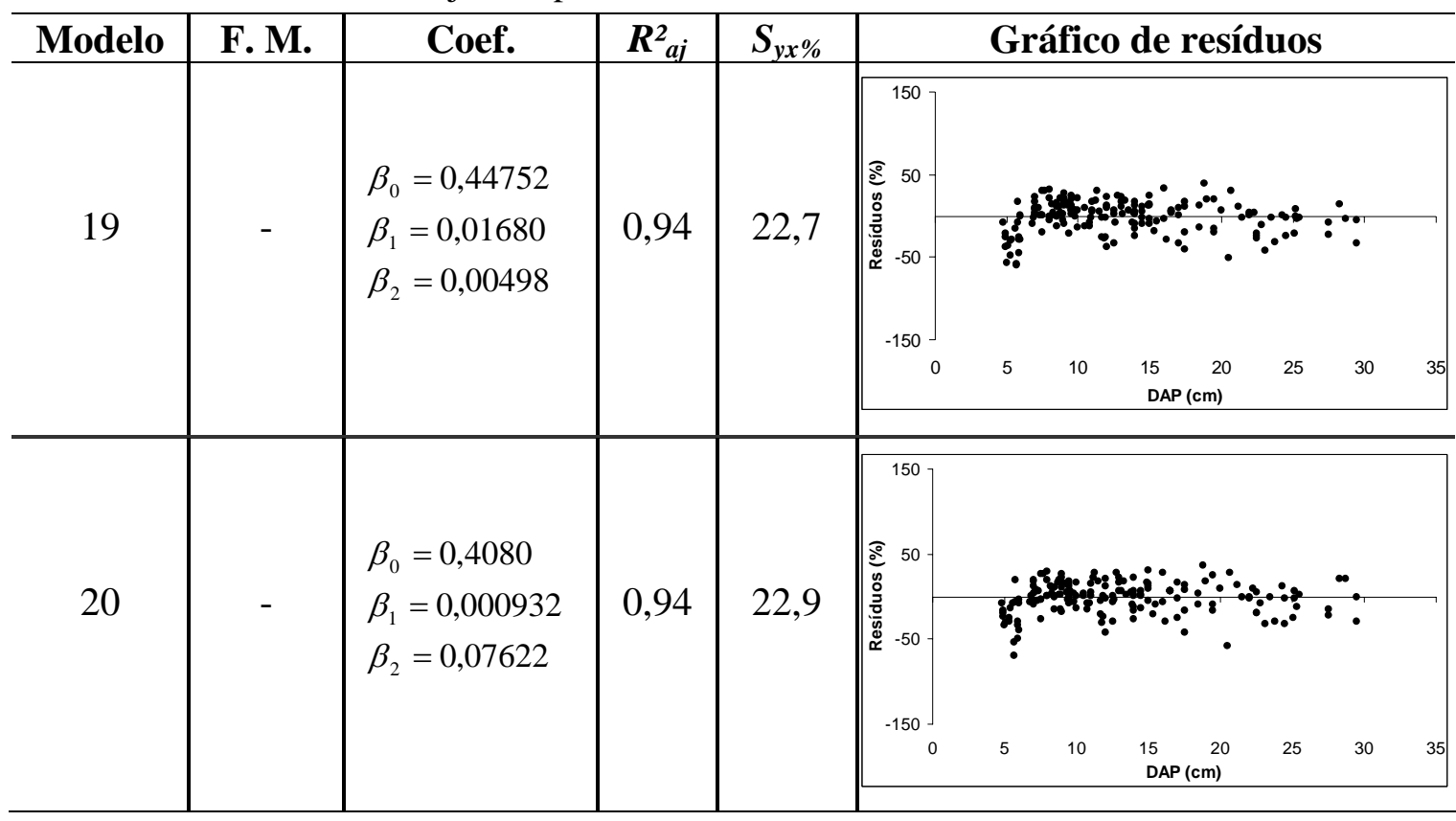

\section{CONCLUSÕES}

Os modelos para estimavas do peso verde e seco da casca, especialmente desenvolvidos neste trabalho, usando o processo Forward, foram os que apresentaram melhor desempenho comparativamente a outros retirados da literatura;

A variável independente que mais contribuiu para a composição dos modelos no processo Forward foi a variável combinada d²h (diâmetro ao quadrado vezes a altura do fuste);

Dentre os modelos selecionados na literatura, apenas os de Schneider serviram como modelos que podem ser usados para estimar o volume de casca em metros cúbicos e em porcentagem e o peso verde da casca, em quilogramas, de bracatinga.

\section{REFERÊNCIAS}

BAGGIO, A. J. Estúdio sobre el sistema agroforestal tradicional de la Bracatinga (Mimosa scabrella Benth.) en Brasil: productividad, manejo de residuos y elaboración de compost. 242f. 1994. Tese (Doutorado em Pascicultura) Departamento de Silvopascicultura, Escuela Tecnica Superior de Ingenieros de Montes, Madrid, 1994

BAGGIO, A. J.; CARPANEZZI, A. A. Exportação de nutrientes na exploração de Bracatingais. Colombo: EMBRAPA Florestas, 1997. p. 3-15. (Boletim de Pesquisa Florestal, 34).

. Quantificação dos resíduos florestais em Bracatingais na região metropolitana de Curitiba, PR. Colombo: EMBRAPA Florestas, 1995. p. 51-66. (Boletim de Pesquisa Florestal, 30/31). 
BAKES, P.; IRGANG, B. Árvores do sul: guia de identificação \& interesse ecológico. Santa Cruz do Sul: Instituto Souza Cruz, 2002. 326p.

BARTOSZECK, A. C. P. S. Evolução da relação hipsométrica e da distribuição diamétrica em função dos fatores idade, sítio e densidade inicial em Bracatingais da Região metropolitana de Curitiba. 214f. 2000. Dissertação (Mestrado em Ciências Agrárias) - Curso de Pós-Graduação em Engenharia Florestal, Universidade Federal do Paraná, Curitiba, 2000.

BATISTA, J. L.; MARQUESINI M.; VIANA, V. M. Equações de volume para árvores de Caxeta (Tabebuia cassinoides) no Estado de São Paulo e sul do Estado do Rio de Janeiro. Scientia Forestalis, Piracicaba, v. 65, p.162-175, 2004.

EMPRESA BRASILEIRA DE PESQUISA AGROPECUÁRIA. Manual técnico da Bracatinga (Mimosa scabrella Benth). Curitiba: Centro Nacional de Pesquisa de Florestas, 1988. 70p. (Série documentos, 20).

FABROWSKI, F. J. Abordagem anatômica, químico-quantitativa e botânica da Bracatinga (Mimosa scabrella Bentham) e suas variedades populares. 87f. 1998. Dissertação (Mestrado em Engenharia Florestal) - Curso de Pós- graduação em Engenharia Florestal, Universidade Federal do Paraná, Curitiba, 1998.

GRODZKI, L.; SOARES, R. C.; BATISTA, A. C.; CARAMORI, P. H. Efeitos do fogo sobre algumas variáveis micrometeorológicas em uma floresta de Bracatinga (Mimosa scabrella Benth.) no município de Colombo, PR. Floresta, Curitiba, v. 34, n. 2, p.151156, 2004.

HUSCH, B.; MILLER, C. I.; BEERS, T. W. Forest mensuration. 3 ed. New York: John Wiley \& Sons, 1982. 402 p.

LAURENT, J. M. E.; CAMPOS, J. B.; BITTENCOURT, S. M. de. Análise técnicoeconômica do sistema agroflorestal da Bracatinga na região metropolitana de Curitiba. Curitiba: Centro Nacional de Pesquisa de Florestas, 1990. 72p. (Série Estudos Florestais, 4).

LOETSCH, F.; ZÖHRER, F.; HALLER, K. E. Forest inventory. München: BLV Verlagsgesellchaft, 1973. 469p. vol. 02.

MACHADO, S. A.; GARCIA, E. R. Determinação do volume da casca em plantações de Pinus taeda. Floresta, Curitiba, v. 15, n. 1, p.17-25, 1984.

MACHADO, S. A.; SILVA, L. C. R da. Análise do volume da casca em porcentagem em Bracatingais de regeneração natural induzida da região metropolitana de Curitiba, PR. Floresta, Curitiba, v. 36, n. 1, p.1-11, 2006.

MEYER, H. A. Bark volume determination in trees. Journal of Forestry, Bethesda, v. 44, n. 12, p.1067-1070, 1946.

NUNES, J. R. S. Análise do volume e da porcentagem de casca em povoamentos de eucaliptos de origem híbrida, segundo a idade, local, espécie e método de regeneração. 103f. 1981. Dissertação (Mestrado em Ciência Florestal) - Curso de PósGraduação em Ciência Florestal, Universidade Federal de Viçosa, Viçosa, 1981. 
REITZ, R.; KLEIN, R. M.; REIS, A. Projeto madeira do Rio Grande do Sul. Porto Alegre: Herbário Barbosa Rodrigues, 1988. 525p.

SCHEIDER, P. R. Modelos de equação e tabelas para avaliar o peso de casca de Acácia negra (Acacia mearnsii Wild). 149f. 1978. Dissertação (Mestrado) - Curso de PósGraduação, Universidade Federal do Paraná, Curitiba, 1978.

SILVA, J. A. A da; PAUlA NETO, F. de. Princípios Básicos de Dendrometria. Recife: Universidade Federal Rural de Pernambuco, 1979. 185p. 